\title{
Homeopatia: história e fundamentos epistemológicos
}

\author{
Homeopathy: its history and epistemological \\ foundations
}

\author{
Hylton Sarcinelli Luz
}

Médico homeopata; pesquisador associado do Instituto de Medicina Social da Universidade do Estado do Rio de Janeiro (IMS/UERJ); membro da Comissão Científica da Associação Médica Homeopática Brasileira

hyltonluz@uol.com.br

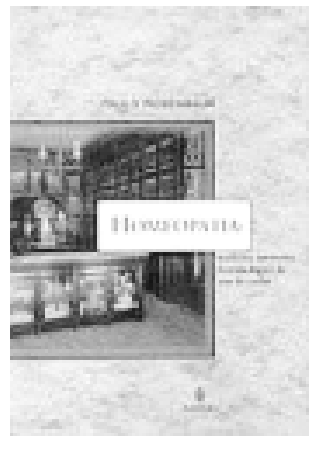

Paulo Rosembaum Homeopatia: medicina interativa bistória lógica da arte de cuidar Rio de Janeiro, Imago, 212p.
$\mathrm{O}$ livro de Paulo Rosembaum, Homeopatia: medicina interativa, história lógica da arte de cuidar, apresenta uma análise desta prática médica, abordada através de suas questões epistemológicas, com a qual visa identificar suas bases, mapear suas necessidades e estabelecer propostas de fundamentação empírica, considerando para tal as diversas alternativas hoje disponíveis. Aponta este levantamento como pré-requisito à elaboração de um programa de pesquisas que seja apto a suportar as características da racionalidade, garantindo-lhe desenvolvimento e validação científica.

O presente trabalho é resultado da dissertação de mestrado apresentada à Faculdade de Medicina da Universidade de São Paulo no Departamento de Medicina Preventiva, defendida em junho de 1999 sob a orientação do prof. José Ricardo C. M. Ayres. Este assinala no prefácio as questões que lhe provocaram a experiência de lidar com este campo do saber e os pontos de vista invocados pelo autor.

Rosembaum inicia contextualizando a homeopatia como a $16^{\underline{a}}$ especialidade médica em número de profissionais registrados no Conselho Federal de Medicina. Fala da expressiva interpenetração nos programas públicos de saúde, mormente no âmbito das ações primárias e da demanda na área de formação de recursos humanos, onde tem programa de qualificação reconhecido e com carga horária equiparável às demais especialidades. Neste sentido refere-se a um "fenômeno de expansão" não como um evento delimitado ao país, mas como um reflexo do panorama internacional onde a prática da homeopatia ganha espaço progressivo. Justificando como uma necessidade irrecorrível a questão de pesquisas científicas para que se sustentem as condutas e os fundamentos que orientam suas intervenções na assistência pública à saúde.

A partir da demanda pública e do reconhecimento dos efeitos positivos pela população, analisa como pertinente as expectativas do meio científico em relação à homeopatia com respeito à validação dos eventos empíricos e das metodologias que são aplicadas na sua consecução. Neste ponto situa o eixo central de seu trabalho, o qual, apoiado na metodologia da epistemologia histórica de Bachelard e Canguilhem, analisa os fundamentos da racionalidade médica homeopática. Por esta via aborda, conseqüentemente, discrepâncias essenciais entre as epistemes que sustentam a racionalidade da biomedicina hegemônica, focada na ordem do gênero 
nosológico, e a da medicina homeopática, centrada na ordem das espécies e da observação das singularidades individuais.

Sobre o movimento homeopático contemporâneo, refere-o como sendo a reconquista de um estatuto institucional mais seguro e politicamente mais bem posicionado, decorrência de uma diversidade de articulações construídas na área da saúde. No entanto, ressalta que o discurso científico e os novos campos de interlocução conformaram uma miríade de dialetos terminológicos e ramificações que impedem que se fale em "a homeopatia", mas sim em "as homeopatias". Justifica a necessidade de sua investigação como meio de escapar da simplificação, reducionista e perigosa, que historicamente polariza correntes homeopáticas que se autodenominam científica e clássica. Aponta na homeopatia contemporânea necessidades que ultrapassam largamente a simples busca de se fazer entender através da assimilação incondicional dos critérios da biomedicina, ou de seguir assepticamente proposições doutrinárias que visam reproduzir "literalmente" o projeto original.

Expõe sobre a construção histórica, política e social do corpus de conhecimento médico homeopático, traçando relações com a história da medicina e das doutrinas médico-biológicas que modulam o atual modelo biocêntrico de saúde. Neste processo analisa algumas das principais doutrinas médicas, em especial, a tradição empírica e vitalista. Perspassa a questão dos saberes hegemônicos e minoritários que transitam ao largo da história, observando "possiblidades epistemológicas originais" e "descobertas negadas" em detrimento da positividade dos eventos patológicos que constroem a historiografia da moderna medicina.

Aborda a construção da epistemologia homeopática através de sua história, analisada através dos conceitos de Kunhn e Lakatos, refere-se a cortes, refluxos, contrapensamentos e choques, inserido-os tanto em dimensões científicas quanto sociopolíticas. Dentro deste contexto apresenta as proposições de Hahnemann como uma ruptura epistemológica, como uma "virada de mesa" que desafia determinadas categorias estáveis na "ciência normal" da medicina de sua época. Analisa o movimento homeopático através de um recenseamento histórico-epistemológico em que discrimina personagens e fatos envolvidos nos processos de irrupção e encapsulação das idéias que vão compor vertentes de pensamento na homeopatia contemporânea.

$\mathrm{Na}$ análise do processo histórico através dos seus aspectos filosóficoconceituais e político-institucionais, aborda o desenvolvimento do saber homeopático em fases, nas quais traça a trajetória de personagens e conceitos. Toma os fatos como idéias e estas como fatos, deste modo, mostra rearranjos e realinhamentos experimentados pelo "programa científico da homeopatia". Situa a homeopatia entre os sistemas médicos privilegiando sua filiação à doutrina conhecida como vitalismo, chamando atenção para as modulações que toma ao longo a história. Aponta a influência desta doutrina nos programas de investigações empíricas presentes até o início do século XX não como um objeto de estudo, mas como uma conseqüência da própria natureza dos fenômenos investigados. Seguindo esta lógica implica as linhas "vitalistas" com a ênfase ao valor da singularidade individual e as questões que interrogam a suficiência dos elementos físicoquímicos para fundamentar a patologia e o processo de restauração da 
saúde. Propõe um aprofundamento de concepções presentes no vitalismo, no âmbito do processo de vida e morte, com perspectiva de se elaborar uma teoria geral dos sistemas vivos.

Constrói um painel de interlocuções para demonstrar a teoria homeopática como tributária direta da filosofia vitalista, estabelece conexões, aponta distinções e examina como o pensamento de Hahnemann é acolhido e rechaçado em diversos pontos da Europa. Indica como este pensamento cria núcleos de resistência, dissemina-se pelo mundo ocidental e origina correntes que alteram o seu eixo epistemológico com adaptações que visam validá-la frente aos postulados da racionalidade médica biocêntrica. Debate sobre o pensar científico e os métodos de argumentação, neste aspecto aborda a recente polêmica que envolve a tese de Beneviste acerca da "memória da água". Aponta para as contribuições da homeopatia na investigação dos aspectos qualitativos da saúde, principalmente no sentido de compreensão do binômio enfermidade/enfermo, particularmente na dimensão antropológica enquanto técnica de intervenção. Nesta, ressalta a sua particularidade de privilegiar como saber médico a fenomenologia da individualidade aplicada ao homem enfermo. Referese ao aproveitamento do conhecimento experimental gerado através de um método empírico que se fundamenta na observação dos sintomas, os quais visam expressar e valorizar a totalidade do indivíduo, conformando parâmetros e critérios que evidenciam aquilo que denomina como "manifestações da vitalidade individual".

É no capítulo dedicado aos perfis teóricos da terapêutica homeopática onde concentra o debate sobre os fundamentos epistemológicos da homeopatia como prática médica. Apresenta inicialmente as questões da predisposição, suscetibilidade e idiossincrasia, traçando o conceito genérico, isto é, dentro do campo médico e científico, assim como os significados no contexto homeopático. Aponta para a relevância que assumem como "elementos operacionais" da doutrina homeopática, tanto com respeito à determinação dos traços que individualizam a causa e o curso dos adoecimentos, quanto e, também, na determinação das singularidades que irão distinguir tanto as entidades nosológicas da mesma espécie entre si, quanto para determinar os elementos que indiciam capacidades responsivas às substâncias aplicadas na terapêutica. Aborda a evolução destes conceitos ao longo da construção empírica do saber homeopático por seu fundador, assim como por comentadores, apontando para aspectos conflitantes e que requerem investigação sistematizada, tanto para sua determinação como elementos semiológicos na clínica, quanto para sua análise frente ao estudo das propriedades das substâncias terapêuticas.

Sobre a similitude como princípio na terapêutica, situa a sua enunciação e aplicação por Hipócrates, assim como o seu percurso ao longo da história, aborda também a sua relação com que o que denomina Foucault como "raciocínio analógico" que perspassa épocas e culturas, apontado-o como uma episteme em si, um modo de pensar, isto é, um solo comum para diversas construções discursivas. Situa as patogenesias, o programa de investigação das substâncias medicinais, como o fundamento praxiológico que rompe de forma definitiva com os sistemas médicos de sua época, tanto por ser pré-requisito à escolha das substâncias, quanto por se 
fundamentar em experimentações com indivíduos não enfermos. Com respeito à opção de experimentar em indivíduos saudáveis, refere-se aos "empíricos" que, na história da medicina, cogitaram ou aplicaram rudimen-tarmente esta proposição. Implica o desenvolvimento e aprimoramento deste método experimental com a origem das doses mínimas e destas com as dinamizações, assim como também com a construção do modelo de observação da totalidade. Esta última conduzindo aos referenciais semiológicos que determinarão a demonstração empírica da concepção de unidade funcional e da singularidade. Ambos como elementos necessários ao estabelecimento das analogias que orientam a técnica de intervenção.

No capítulo em que aborda os desafios epistemológicos que estão propostos à homeopatia faz o que chama de "levantamento preliminar e exploratório" de problemas que precisam retornar para o âmbito da pesquisa e reflexões em homeopatia. Destacamos: "variabilidade individual e terapêutica", sobre a qual enumera um conjunto importante de aspectos que precisam ser aprofundados na técnica da individualização, visando garantir clareza e precisão para os critérios que se envolvem com a análise e a depuração dos elementos "subjetivos" deste processo. Em enfermidades crônicas faz considerações acerca da origem etiológica dos sintomas, isto é, aos fatores endógenos e exógenos que geram o complexo sintomático. Analisa e debate aspectos que dizem respeito à questão da norma e da construção do patognomônico, tanto na enfermidade, quanto no sujeito. Aponta nesta última os elementos centrais que problematizam a construção de uma totalidade individualizante, inserindo aí a questão da regularidade do diverso na seriação dos eventos em um dado ordenamento temporal. Neste contexto percorre as regras instituídas e destituídas ao longo da história da prática homeopática. Assim, indica o método de apreensão do sujeito através de elementos singularizantes presentes na evolução das histórias clínicas, como mais um campo de investigação necessária.

Em "homeopatia como medicina do sujeito" contextualiza o momento histórico da medicina em que é feita esta proposição, definindo o seu significado e estabelecendo distinções, assim como também nexos com outras propostas passadas e presentes. Em "homeopatia: medicina interativa, por uma semiologia do sujeito", avança sobre a questão da construção das histórias clínicas e da abrangência das concepções de totalidade do objeto observado pela medicina, deste modo adentra a noção de limites do campo de observação e conseqüentemente da definição do próprio objeto. O último tópico refere-se a um "neovitalismo" quando discorre sobre o curso desta idéia no presente e as repercussões dos conceitos de totalidade e unidade sobre as ciências da vida. Afirma ser possível considerar o vitalismo como conceito em transição que aguarda por desenvolvimentos da ciência para que se expliquem os fenômenos relacionadas às ultradiluições dos medicamentos dinamizados. Conclui o capítulo referindo-se aos mecanismos vivos e artificiais, onde aborda a questão da autoconservação, auto-regulação e dos mecanismos de interação ativa com o meio, debatendo o conceito de organismo como uma máquina viva e radicalmente distinta da artificial. Adentra assim nos aspectos mecanicistas do discurso médico e em suas analogias operativas 
oriundas de ciências auxiliares que, aplicadas à biologia, tutelam os meios de investigação com elementos quantitativos rígidos e incapazes de expressar as qualidades inatas aos eventos vivos. Neste ponto retorna às questões do vitalismo e da carência atual da ciência para refletir as intuições homeopáticas acerca do fenômeno vital, afirmandoo como de interesse de todos, não apenas homeopatas ou não homeopatas, médicos ou não médicos, mas também de filósofos ou tecnólogos, poetas ou cientistas etc.

Conclui seu livro afirmando que a homeopatia não é um sistema auto-suficente e acabado, mas sim uma ciência e uma prática em construção. Apresenta as possíveis linhas de pesquisa a serem seguidas na busca da fundamentação científica da intuição clínica da homeopatia, apontando as vertentes da experimentação, dos estudos epidemiológicos e dos seguimentos biográficos prospectivos; finaliza referindo-se às fronteiras epistemológicas. 